International Journal of Current Advanced Research

ISSN: O: 2319-6475, ISSN: P: 2319 - 6505, Impact Factor: SJIF: 5.995

Available Online at www.journalijcar.org

Volume 6; Issue 3; March 2017; Page No.2326-2330

DOI: http://dx.doi.org/10.24327/ijcar.2017.2330.0001

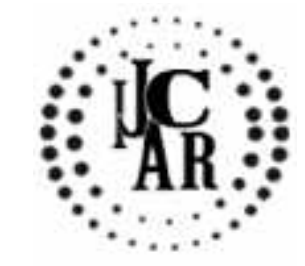

Research Article

\title{
DANDY WALKER MALFORMATION WITH UNUSUAL FINDINGS IN FETAL AUTOPSIES
}

\author{
KV Amrutha ${ }^{*}$., Sharma $A^{2}$., Abraham $\mathrm{J}^{3}$ and Kaur Anupriya ${ }^{2}$ \\ ${ }^{1}$ Department of Anatomy, Yirgalem Medical College and Hospital, Ethiopia, Addis Ababa \\ ${ }^{2}$ Department of Anatomy, Government Medical College and Hospital, Chandigarh 32, India \\ ${ }^{3}$ Department of Anatomy, School of Medicine, Wollega University, Ethiopia, Addis Ababa
}

A R T I C L E I N F O

Article History:

Received $10^{\text {th }}$ December, 2016

Received in revised form $7^{\text {th }}$ January, 2017

Accepted $11^{\text {th }}$ February, 2017

Published online $28^{\text {th }}$ March, 2017

Kye Words:

\begin{abstract}
A B S T R A C T
The Dandy-Walker malformation is a rare group of congenital abnormalities of brain, typically involving the fourth ventricle and the cerebellum. The Dandy-Walker malformation has an estimated prevalence of about 1 in 25,000 to 35000 live births with a slight female preponderance and is responsible for $4-12 \%$ of infantile hydrocephalus. Dandy-Walker malformation is frequently associated with other intracranial anomalies such as agenesis of the corpus callosum, holoprosencephaly, occipital encephaloceles and ocular abnormalities. Extra-cranial anomalies include polycystic kidneys, cardiovascular defects, polydactyly and cleft palate. Present study was conducted on 1200 fetuses obtained from department of Obstetrics and Gynecology, Government medical college and hospital, Chandigarh. Autopsy was done in department of Anatomy, GMCH Chandigarh. In our present study the incidence of Dandy walker syndrome was $0.4 \%$ (out of 1200 fetuses DWS was noted in 5 fetuses). Associated anomalies were noted in each case. Prenatal diagnosis of DWS is important to detect and avoid further complications in life.
\end{abstract}

Copyright $@ 2017$ KV Amrutha. This is an open access article distributed under the Creative Commons Attribution License, which permits unrestricted use, distribution, and reproduction in any medium, provided the original work is properly cited.

\section{INTRODUCTION}

Dandy-Walker malformation is a rare congenital abnormality of brain, characterized by hypoplasia or absence of cerebellar vermis, cystic dilatation of fourth ventricle and hydrocephalus 1. Dandy-Walker malformations (DWM) accounts for about 1 in 25,000 to 35000 live births ${ }^{2}$. Sutton was the first one to described DWM, which was further described by Dandy and Black fan followed by Tagart and Walker. Finally in 1954 Benda labeled this disease as Dandy Walker ${ }^{3}$. Associated congenital anomalies such as cleft palate, micrognathia, hypertelorism, cardiac anomalies, renal and skeletal malformation are said to be present in $48 \%$ cases $^{4}$. In the present cases DWS is associated with unusual associations such as agenesis of corpus callosum, agenesis of vermis, agenesis of spleen along with some associated anomalies such as microphtalmia, cardiac anomalies, duplicated ureter, diaphragmatic hernia. DWS is a frequent cause of termination of fetus diagnosed prenatally ${ }^{5}$.

\section{MATERIALS AND METHODOLOGY}

The present study was conducted on 1200 humans fetuses (since Jan 2008- july 2016) in the Department of Anatomy, Government Medical College \& Hospital, Chandigarh.

\section{*Corresponding author: KV Amrutha}

Department of Anatomy, Yirgalem Medical College and Hospital, Ethiopia, Addis Ababa
Fetuses were sent by the Department of Obstetrics \& Gynaecology of the same institute for routine autopsy. These included the spontaneous abortions, stillbirths, intra-uterine deaths and therapeutic abortions after recognition of congenital malformations on ultrasonography or by karyotyping. The consent was taken from the parents. Before autopsy relevant maternal and family history along with antenatal USG findings were recorded. The sex, gestational age of fetus were noted. External features were noted and photographed. Radiography was also done in revelant cases. Internal examination of the fetus was done after performing routine autopsy procedure and photographed .The associated anomalies, found, if any, was also noted

\section{CASE REPORTS}

\section{Case 1}

First case reported was a male fetus of $19^{+6}$ weeks. Mother of fetus was 22yrs old, primi gravida. Medical history and past history of parents were not suggestive of any etiological factors responsible for the defect. The indication of MTP was DWS.

\begin{tabular}{|c|c|}
\hline External examination & Internal examination \\
\hline $\begin{array}{l}\text { - Large head } \\
\text { - bilateral club foot with over } \\
\text { ridding of } 4^{\text {th }} \text { toe on right } \\
\text { side and } 2^{\text {nd }} \text { toe on left side. }\end{array}$ & $\begin{array}{l}\text { - } \text { Cerebrum had pachygyria } \\
\text { - hypoplasia of cerebellum making } \\
\text { floor of fourth ventricle visible } \\
\text { - Right side cerebral hemisphere was } \\
\text { smaller than left } \\
\text { - posterior cranial fossa appeared } \\
\text { larger }\end{array}$ \\
\hline
\end{tabular}




\section{Case 2}

$22^{+1}$ week female fetus born to $20 \mathrm{yr}$ old mother who had a obstetric history of $\mathrm{G}_{5} \mathrm{P}_{1} \mathrm{~A}_{4} \mathrm{~L}_{1}$. Her first child was born alive but died at the age of $2^{1 / 2} \mathrm{yrs}$, due to bilateral retinoblastoma.In rest of the pregnancies spontaneous abortion occured at 2-3 months. In present case indication for MTP was Dandy Walker Syndrome, Microphtalmia, pyelectasis, echogenic shadow in heart, VSD, club foot on ultra sonogram. Maternal history showed that she had unilateral retinoblastoma which got operated at age of 6yrs.Paternal history showed excessive use of drugs, tobacco, smoke and anti depressant drugs.

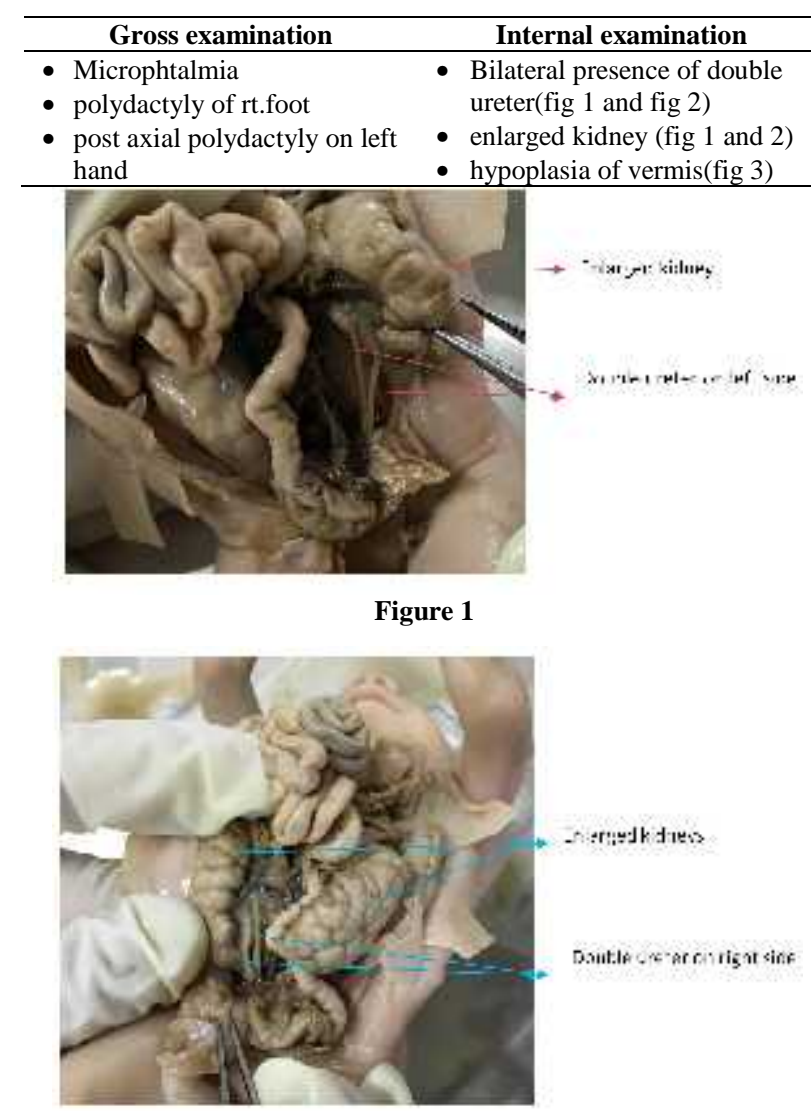

Figure 2

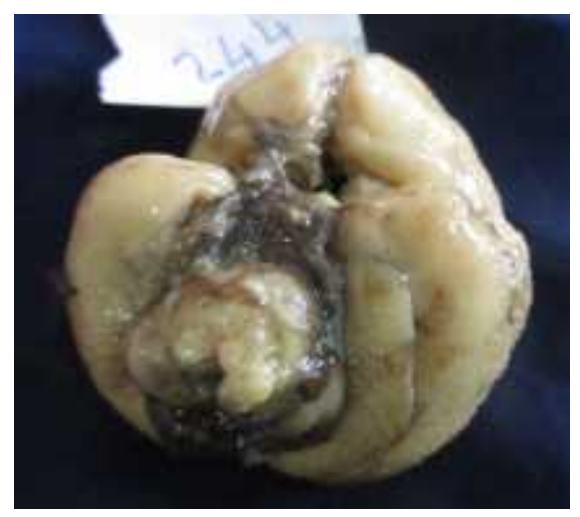

Figure 3 showing hypoplasia of vermis

\section{Case 3}

$21^{+2}$ week female fetus born to $22 \mathrm{yr}$ old mother. Medical history and past history of parents were not suggestive of any etiological factors responsible for the defect. The indication of MTP was DWS, enlarged cistern magna, hypoplasia of $b / 1$ cerebellar hemisphere, aplasia of vermis

\begin{tabular}{|c|c|}
\hline Gross examination & Internal examination \\
\hline $\begin{array}{l}\text { - Bilateral long fingers, } \\
\text { - camptodactyly, } \\
\text { - contractus elbow and wrist(fig } \\
-4) \\
\text { - B/L CTEV,Poor muscle } \\
\text { bulk(fig 4) }\end{array}$ & $\begin{array}{l}\text { - Lateral and fourth ventricle } \\
\text { small compared to normal } \\
\text { (fig 5) }\end{array}$ \\
\hline
\end{tabular}
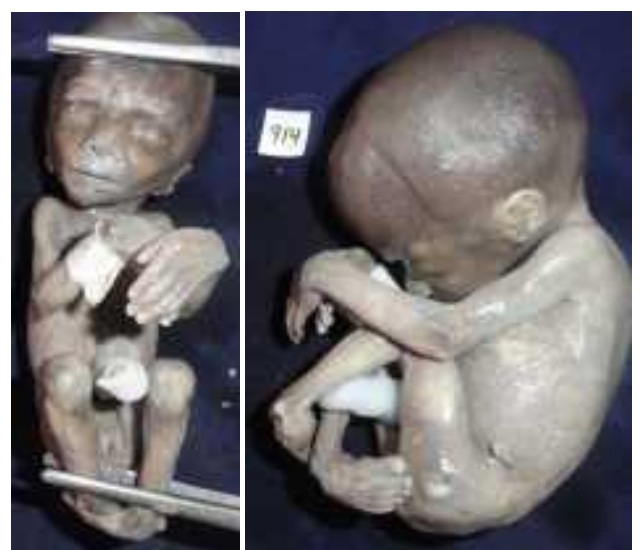

Figure 4 showing contractus elbow and wrist B/L CTEV, Poor muscle bulk

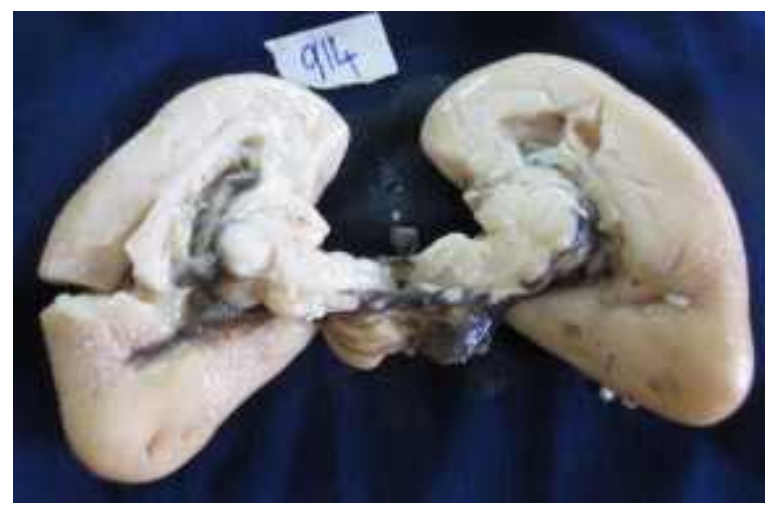

Figure 5 Lateral and fourth ventricle small compared to normal

Case 4

22 weeks female fetus born to yr mother, who had a obstetric

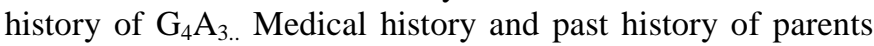
were not suggestive of any etiological factors responsible for the defect. The indication of MTP was DWS

\begin{tabular}{ll}
\hline \multicolumn{1}{c}{ Gross examination } & \multicolumn{1}{c}{ Internal examination } \\
\hline & - Left side diaphragmatic hernia (fig \\
& 6)with herniation with herniation of \\
& intestine,stomach,liver to thoracic \\
& cavity (fig -7) \\
& - Asplenia, \\
& - Horizontally placed left lung-left lung \\
& hypoplasia,(fig 8) \\
& - rt lung with abnormal lobulation. \\
& - CVS-horizontally placed heart (fig 8). \\
- Short neck, & aorta and pulmonary trunk arising \\
- flat occiput, & from rt.ventricle.(fig 9 and fig 10) \\
- retro microngnatia & - Lt.ventricle and atrium hypoplastic \\
- ear dysmorphic, & CNS-asymmetric posterior and middle \\
- rt.ear shows pre auricular & cranial fossa \\
tag. & asymmetric cerebral hemisphere(fig \\
& - li) \\
& - left cerebral hemisphere larger than \\
& right(fig 12) \\
& - left temporal pole of cerebrum absent \\
& - Sbsence of corpus callosum(fig 13) \\
& - Vermil hind brain \\
& inferior surface of cerebellum \\
&
\end{tabular}




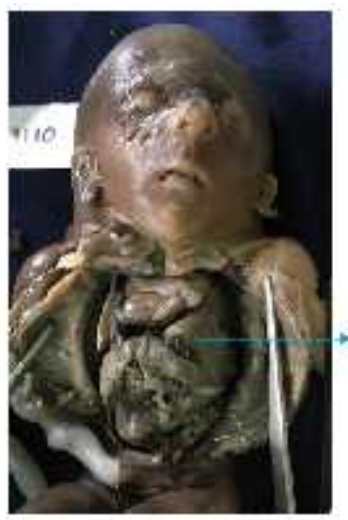

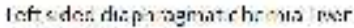
inth socic sovity

Figure 6 showing left sided diaphragmatic hernia

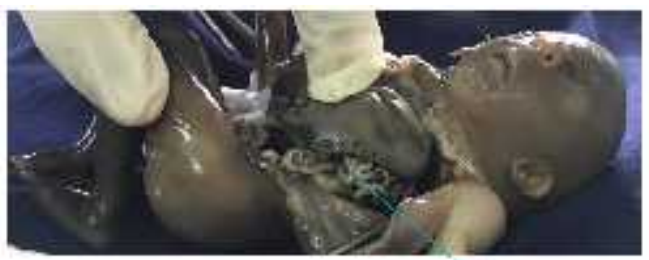

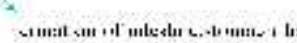
thenu: : cu: it:

Figure -7

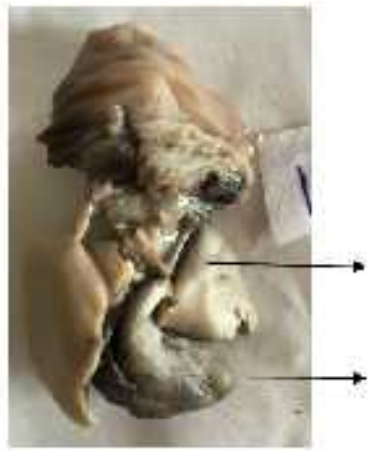

lofi. Iune hyporplazia.

honsatally plased heart.

Figure 8

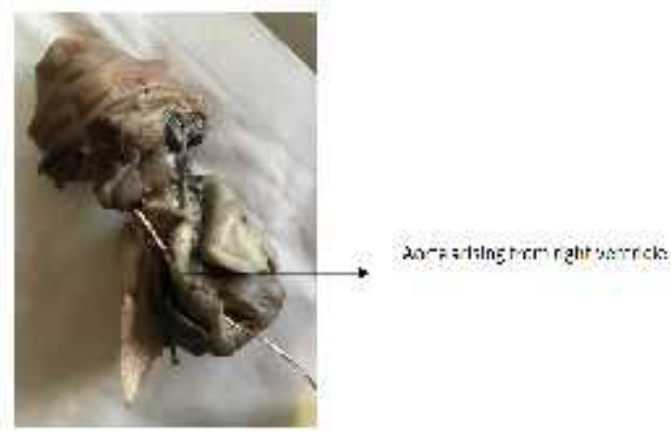

Figure 9

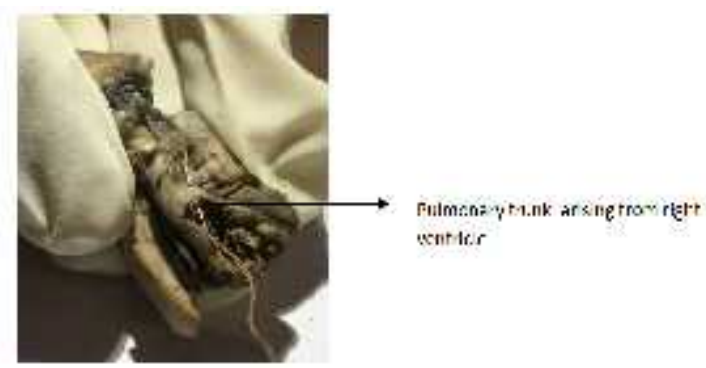

Figure 10

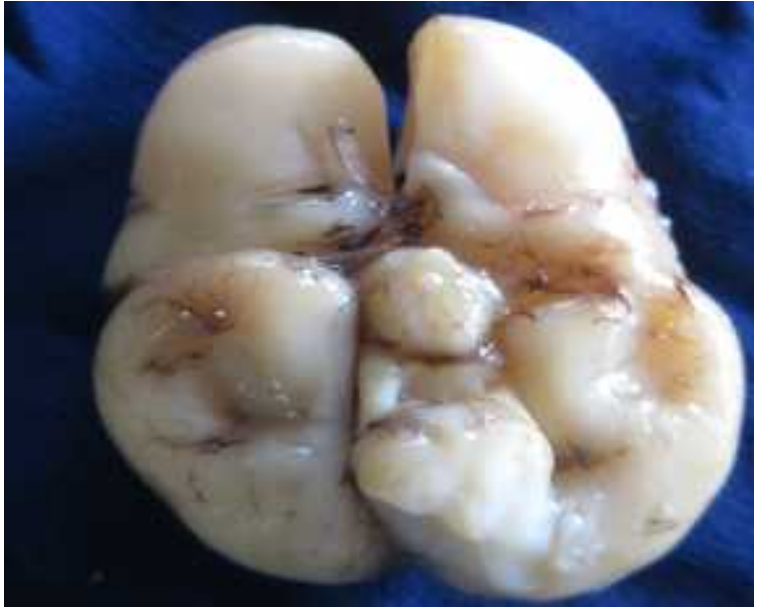

Figure 11 assymetric cerebral hemisphere

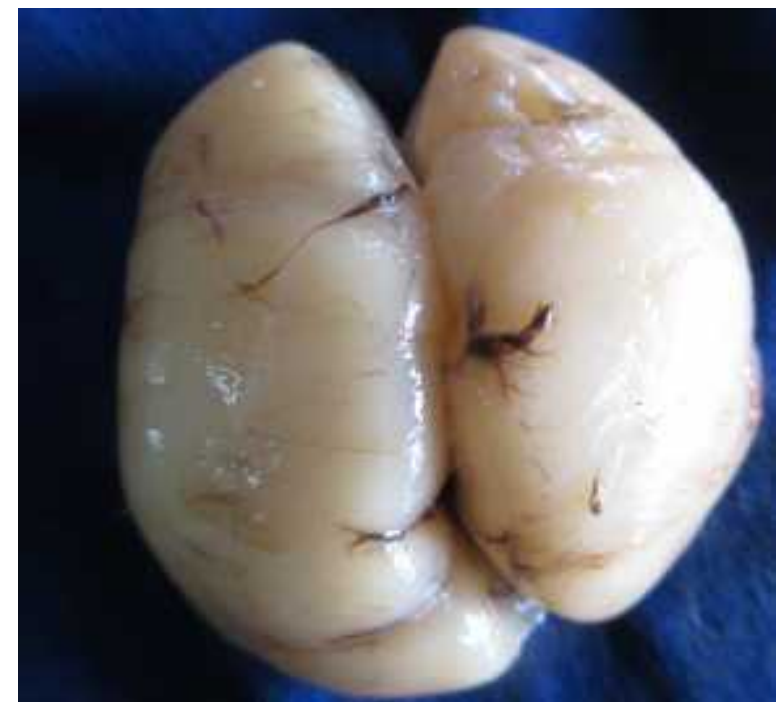

Figure12 left cerebral hemisphere larger than right

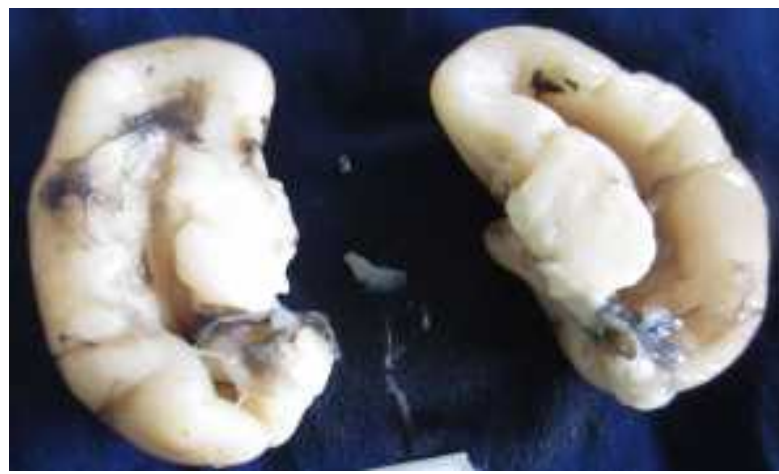

Figure 13 absence of corpus callosum

Case 5

$16+3$ weeks male fetus born to $25 \mathrm{yr}$ old mother..The indication of MTP was DWS, abberent rt subclavian artery complex cardiac malformation. she had a medical history of viral infection for 2 week.

\begin{tabular}{ccc}
\hline Gross examination & \multicolumn{1}{c}{ Internal examination } \\
\hline$\bullet$ normal & $\bullet$ & $\begin{array}{l}\text { heart horizontally placed with right } \\
\text { atrium and ventricle enlarged( fig 14) }\end{array}$ \\
\hline
\end{tabular}

Out of 1220 autopsies, dandy walker malformation was found in 5 fetuses $(0.4 \%)$

\begin{tabular}{|c|c|}
\hline \multicolumn{2}{|c|}{$\begin{array}{l}\text { Incidence of dandy } \\
\text { walker syndrome }\end{array}$} \\
\hline Male & Female \\
\hline $2(40 \%)$ & $3(60 \%)$ \\
\hline
\end{tabular}




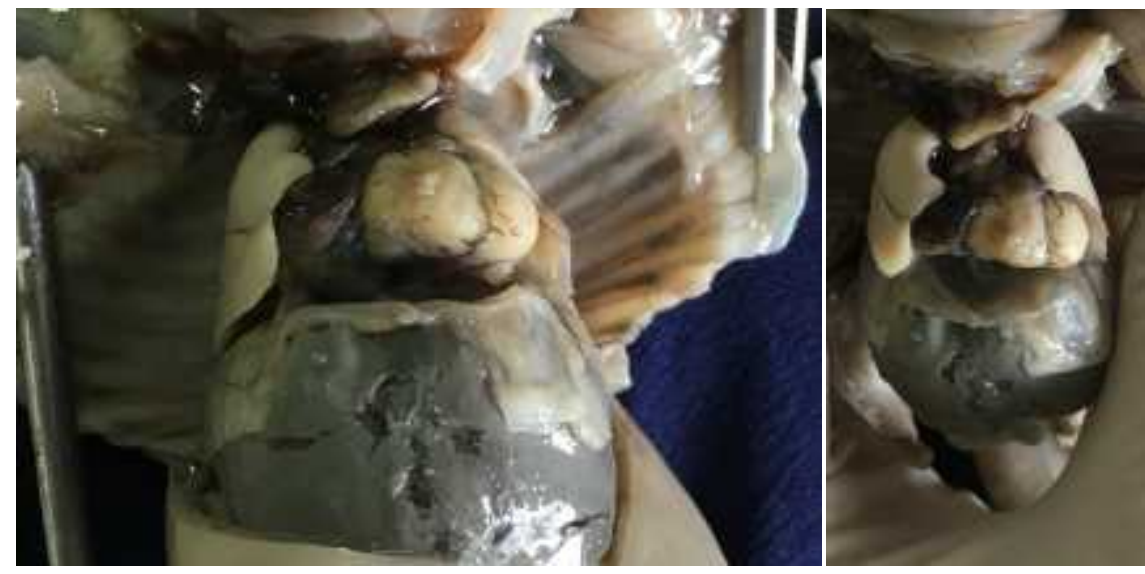

Figure 14 showing horizontally placed heart with right atrium and ventricle enlarged

\section{DISCUSSION}

The Dandy-Walker complex is a rare and group of congenital intracranial malformation which comprises abnormalities of the posterior fossa. It can be classified as

1. Dandy-Walker malformation -which includes cystic dilatation of the 4 th ventricle, partial or complete agenesis of the cerebellar vermis and an enlarged posterior fossa.

2. Dandy-Walker variant -cystic posterior fossa mass with variable hypoplasia of the cerebellar vermis and no enlargement of the posterior fossa

3. Megacisterna magna -enlarged cisterna magna with normal cerebellar vermis and fourth ventricle. DWM accounts for $12 \%$ of all cases of congenital hydrocephalus ${ }^{6}$.

The Dandy-Walker malformation has a slight female preponderance .In present study also we came across female preponderance, out of 5 fetuses with DWS, 3 was female and 2 male.DWS accounts for about 1:30,000 live births and is responsible for $4-12 \%$ of infantile hydrocephalus ${ }^{7}$.

Philips JJ et al. in his study on DWM noted extra CNS abnormalities in 30 out of 44 cases. These abnormalities included congenital diaphragmatic hernia, renal anomalies, congenital heart defects \& extremity anomalies such as clubfoot. Agenesis of corpus callosum was reported in one case. Various other authors had mentioned about associated CNS anomalies such as ventriculomegaly, corpus callosum agenesis, abnormalities of gyri, microcephaly, occipital meningocele and encephalocele ${ }^{8}$. Murray et al in his study noted other extra-cranial anomalies such as polycystic kidneys, cardiovascular defects, polydactyly and cleft palate ${ }^{9}$. In our present study agenesis of corpus callosum was noted in one case, cardiac anomalies were noted in two cases, renal anomalies in one case, polydactyly in one case, CTEV in one case.

According to Dandy and Walker dilatation of ventricular system occurred due to atresia of the foramina of Luschka and Magendie.How ever Benda suggested that it's difficult to understand how atresia of these foraminas would lead to cerebellar vermis hypoplasia ${ }^{10,11}$. Gardner et al gave a more clarified theory regarding hypoplasia of vermis. He proposed that early dilatation and herniation of rhombenephalic roof can be due to overproduction of CSF at fourth ventricle, this dilatation due to overproduction at the level of fourth ventricle can cause compression and secondary hypoplasia of cerebellar vermis ${ }^{12}$. Hirsch et al 1 suggested that malformation can be classified into communicating and non communication depending on whether the foramina of Luschka and Magendie are open or closed, Non communicating is related with variying type of hydrocephalus ${ }^{13}$

Kolble and philips reported a very rare case in which there was association of DWS with congenital absence of spleen. Congenital absence of spleen is rare and life threatening condition. In our present finding one of the case there was asplenia associated with congenital unilateral diaphragmatic hernia ${ }^{8,14}$.

Chowdareddy N. et al reported a case of DWS, in 26 week female fetus, associated with congenital diaphragmatic hernia with herniation of liver, stomach \& spleen into left hemithorax, hypoplasia of lung, they also noted Hydrocephalus, Absent corpus callosum \& vermis, Cyst. Congenital diaphragmatic hernia $(\mathrm{CDH})$ is an uncommon birth defect with incidence of 1:2000 to1:3000 births, of which $96 \%$ are Bochdalek type ${ }^{15}$. We had also got similar findings in one of our case -22 week female fetus with left diaphragmatic hernia with herniation of liver, stomach and intestine to left thoracic cavity, absent corpus callosum, absent left temporal pole of cerebral hemisphere, large left cerebral hemisphere along with CVS defects.

Murray et al in his study on etiologic heterogeneity of DWS suggested that environmental factors, such as viral infection, alcohol, and diabetes, have been playing a role in its etiology ${ }^{9}$.In our study we came across two cases with such a history .In one of the case mother had medical history of viral infection .In another case paternal history showed excessive use of drugs, tobacco, smoke and anti depressant drugs.

Various authors had mentioned about DWS association with cardiovascular anomalies. According to Hirsch JF et al 1 anomalies associated with DWS includes encephaloceles, polycystic kidneys, and cardiovascular defects (mainly ventricular septal defects ${ }^{13}$. According to Golden JA et al 26$38 \%$ of cases with DWS cases had extracranial manifestation including ventricular septal defect, patent ductus arteriosus, ASD, pulmonary stenosis, intestinal anomalies and renal defects ${ }^{16}$. In our case, we came across a fetus with CVS defect we noted that aorta and pulmonary trunk were arising from right ventricle and left ventricle and left atrium were 
hypoplastic, same case had a left sided congenital diaphragmatic hernia with liver, stomach, intestines herniating into thoracic cavity, asplenia.

Eventhough hydrocephalus is considered as a major diagnostic element of DWS, recent research had suggested that in most cases hydrocephalus is not present at the time of birth and they had noted that hydrocephalus develops usually at first month of life. In such cases the diagnosis can only be made prenatally depending on the posterior cranial fossa abnormalities $^{13}$. Positive diagnosis before viability gives a option for pregnancy termination.

Generally, DWS is treated with surgery, especially when there is concomitant hydrocephalus as well as signs of intracranial hypertension. There are a number of surgical options, ranging from a ventriculo peritoneal shunt to fenestration of the cystic membrane, a primary cystoperitoneal shunt or a ventriculocysto-peritioneal shunt ${ }^{17}$.

\section{CONCLUSION}

Agenesis of corpus callosum interference with medullary control of respiration which often results in respiratory failure

14. DWS association with congenital diaphragmatic hernia and asplenia is very rare ultrasound $\&$ pathologic examination are indicated in DWS for screening of concurrent cranial and extra cranial malformation. Proper diagnosis of DWS is necessary for further treatment Eventhough hydrocephalus is considered as a diagnostic element in DWS in most cases it appears after birth .So the posterior cranial fossa abnormalities should be noted prenataly as a diagnostic tool.

\section{References}

1. Surekha U Arakeri, Himanshu Mulay .Dandy Walker Syndrome with Unusual Associated Findings in a Fetal Autopsy Study. JKIMSU, Vol.4,No.1, jan-march 2015

2. Lavanya T, Cohen M, Gandhi SV, Farrell T, Whitby EH. A case of a Dandy-Walker variant: the importance of a multidisciplinary team approach using complementary techniques to obtain accurate diagnostic information. Br J Radol 2008; 81: 242-245

3. Tadakamdia J, Kumar S, Mamatha GP. Dandy-Walker Malformation: An Incidental Finding. Indian Journal of Human Genetics 2010; 16: 33-35

4. Dr Shweta Mane, Dr Shruti Rao, Dr S.D Ladi, Dr S.S Aphale.Innovative DANDY WALKER SYNDROME: CASE REPORT. Journal of Medical and Health Science 4 : 1 Jan - Feb(2014) 309-311
5. Alessandro et al. dandy walker malformation and Wisconsin syndrome: novel case add further insight into the genotype-phenotype correlation of $3 q 23 q 25$ deletions. Orphanet journal of rare diseases .2013,8:75

6. Fischer EG: Dandy-Walker syndrome: An evaluation of surgical treatment. J Neurosurg 39:615, 1973. 13.

7. Osenbach RK, Menezes AH. Diagnosis and management of the Dandy-Walker malformation: 30 years of experience. Pediatr Neurosurg 1991; 18:17985.

8. Philips JJ, Mahony BS, Siebert JR, Lalani T, Flinger CL, Kapur RP. Dandy-Walker malformation complex: correlation between ultrasonographic diagnosis and postmortem neuropathology. Obstet Gynecol 2006; 107: 685-693

9. Murray JC, Johnson JA, Bird TD. Dandy-Walker malformation: etiologic heterogeneity and empiric recurrence risk. Clin Genet 1985;28:272-6

10. Dandy WE: The diagnosis and treatment of hydrocephalus due to occlusion of the foramina of Magendie and Luschka. Surg Gynecol Obstet 32:112, 1921.8

11. Taggart JK, Walker AE: Congenital atresia of the foramens of Luschka and Magendie. AMA Arch Neurol Psychiatr 48:583, 1942.

12. Gardner E, O'Rahilly R, Prolo D: The Dandy Walker. and Arnold-Chiari malformations: Clinical, developmental and teratological considerations. Arch Neurol 32:393, 1975

13. Hirsch JF, Pierre-Kahn A, Renier D, et al:: The DandyWalker malformation: A review of 40 cases. J Neurosurg 61:515, 1984

14. Kolble N, Wisser J, Kurmanavicius J, Bolthauser E, Stallmach T, Huch A et al. Dandy-Walker Malformation: prenatal diagnosis and outcome. Prenat Diagn 2000; 20: 318-327.

15. Chowdareddy n.1, anil kumar y.c.1, nihala1, manoj1, gopal k.1, ravichander1 and neetha r. A case of dandy walker malformation with congenital diaphragmatic hernia - a rare variant- case report. Indian journal of medical case reports 2013 vol.2 (4) october-december, pp.63-64

16. Golden JA, Rorke LB, Bruce DA (1987) DandyWalker syndrome and associated anomalies. Pediatr Neurosci 13: 38-44

17. Kumar R, Jain MK, Chhabra DK. DandyWalker syndrome: different modalities of treatment and outcome in 2 cases. Childs Nerv Syst 2001; 17: 348-52.

\section{Please cite this article in press as:}

KV Amrutha., Sharma A., Abraham J and Kaur Anupriya (2017), Dandy Walker Malformation with Unusual Findings In Fetal Autopsies, International Journal of Current Advanced Research, 6(3), pp. 2326-2330.

. http://dx.doi.org/10.24327/ijcar.2017. 2330.0001 